\title{
Fragment-like chloroquinolineamines activate the orphan nuclear receptor Nurr1 and elucidate activation mechanisms
}

Sabine Willems ${ }^{1}$, Julia Ohrndorf ${ }^{1}$, Whitney Kilu ${ }^{1}$, Jan Heering ${ }^{2}$, Daniel Merk ${ }^{1 *}$

${ }^{1}$ Institute of Pharmaceutical Chemistry, Goethe University Frankfurt, Max-von-Laue-Str. 9, 60438 Frankfurt, Germany

2 Fraunhofer Institute for Translational Medicine and Pharmacology ITMP, Theodor-Stern-Kai 7, 60596 Frankfurt, Germany

- Supporting Information -

\section{Table of contents}

Supporting Figures and Tables .................................................................. $\mathrm{S} 2$

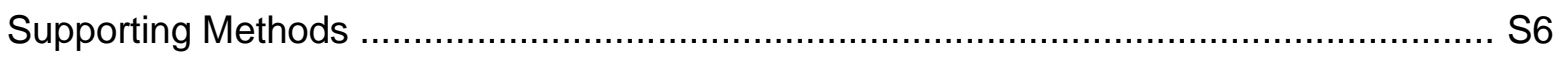




\section{Supplementary Figures and Tables}
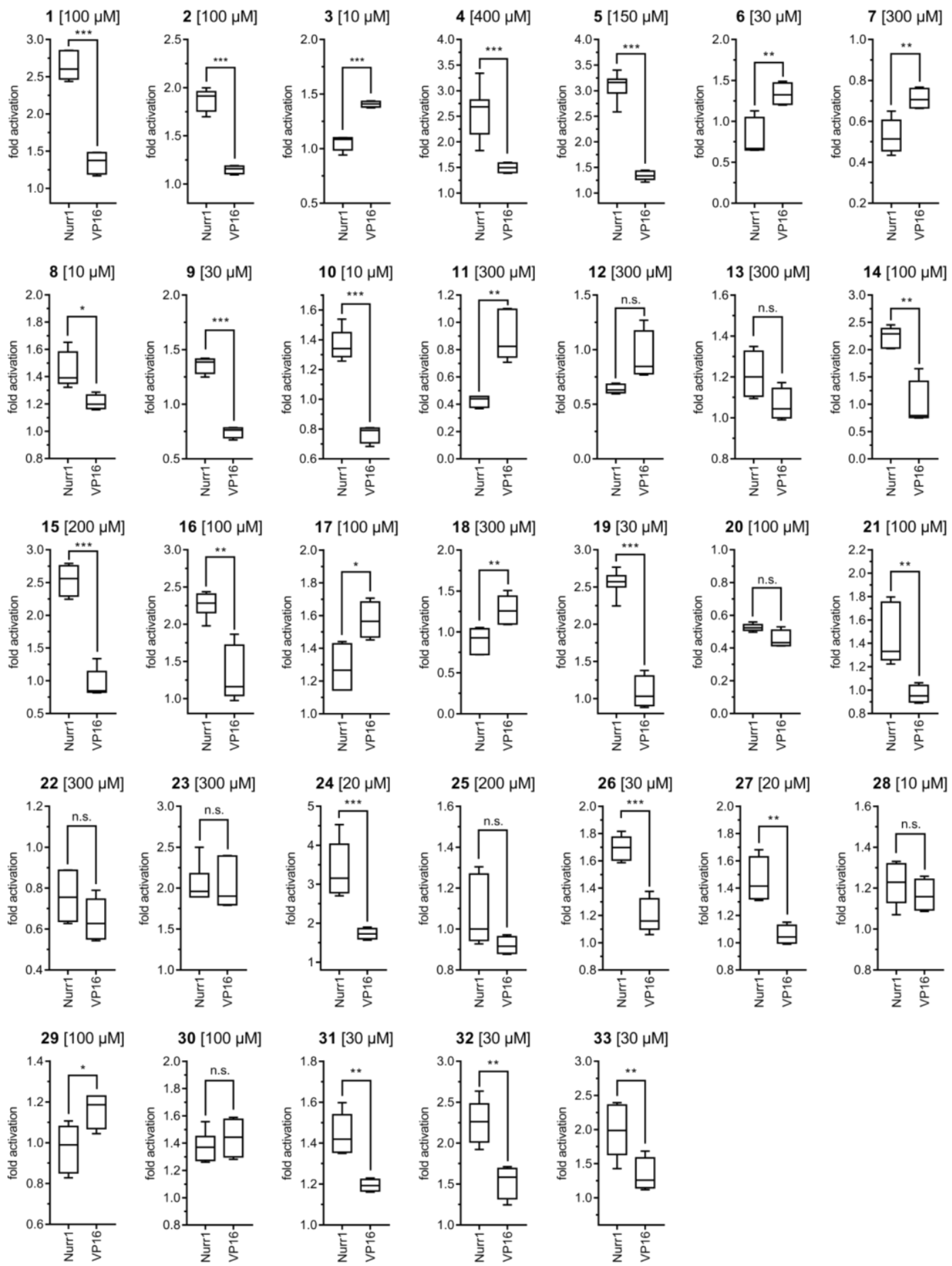

Figure S1. Control experiments employing a Gal4-VP16 hybrid receptor were performed for all tested compounds to confirm or refute Gal4-Nurr1 mediated activity in the cellular hybrid reporter gene assay. Boxplots show: center line, median; box limits, upper and lower quartiles; whiskers, $\min / \max ; n \geq 4 .{ }^{*} p<0.05,{ }^{* *} p<0.01{ }^{* * *} p<0.001$ (t-test). 

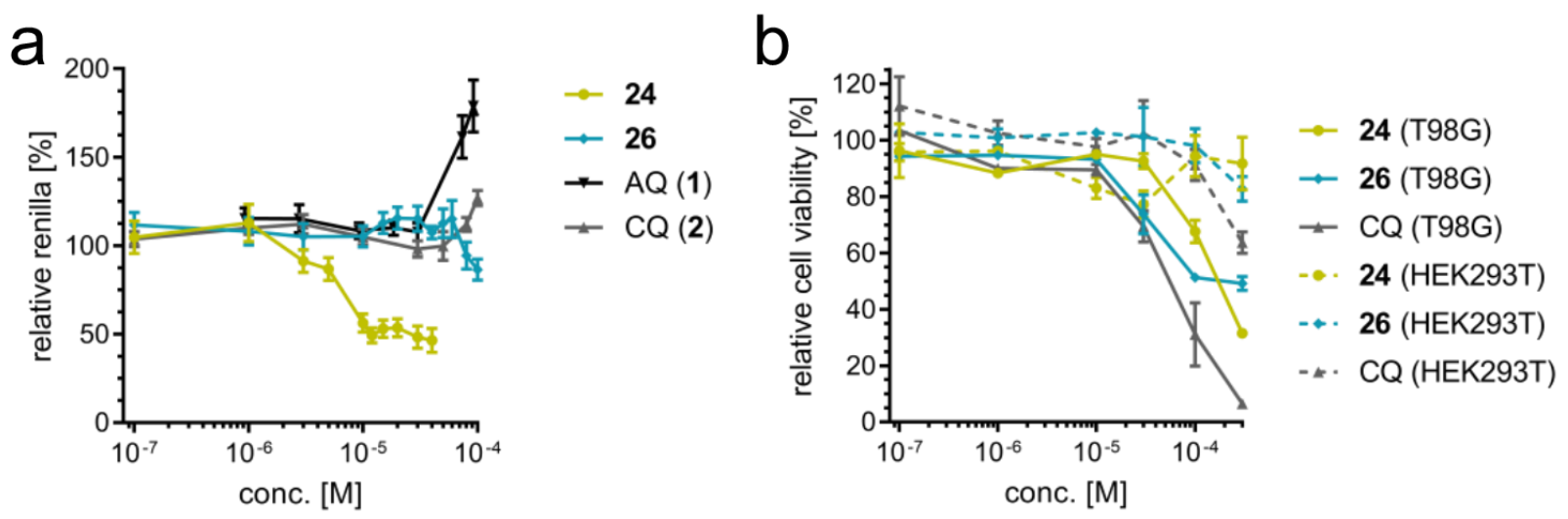

Figure S2. Nonspecific effects and cytotoxicity of Nurr1 agonists. (a) Relative renilla luminescence from cellular Gal4 hybrid reporter gene assay in HEK293T cells compared to DMSO $0.1 \%$ control reveals pronounced non-specific effects on transcriptional activity for $A Q$ and 24 . Data are the mean \pm SEM; $n \geq 3$. (b) Treatment of human astrocytes (T98G) and HEK293T cells with increasing concentrations of $\mathbf{2 4}$ and $\mathbf{2 6}$ revealed no cytotoxicity up to $300 \mu \mathrm{M}$ in HEK293T cells and increasing toxicity from $100 \mu \mathrm{M}$ in astrocytes. Cell viability was determined by a WST-1 assay. CQ (2) is shown for comparison. Data are the mean \pm SEM; $n \geq 3$.

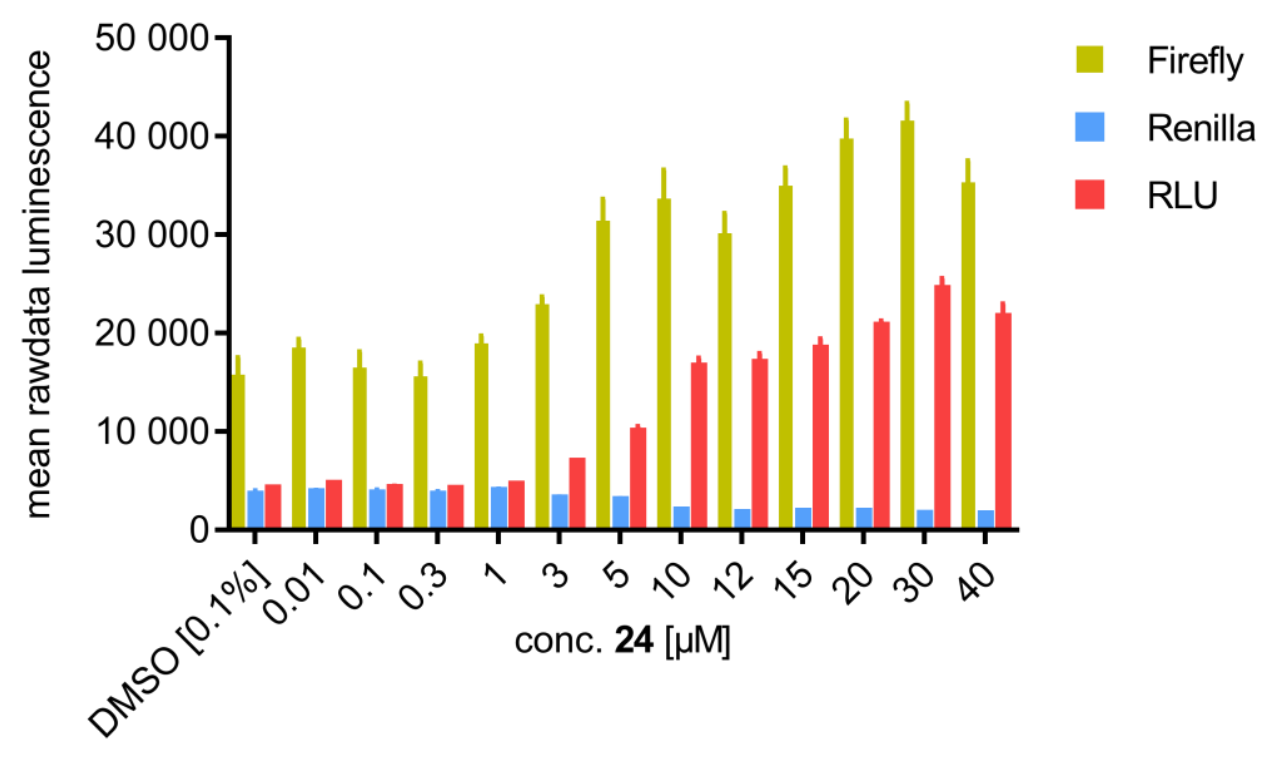

Figure S3. Raw luminescence data for $\mathbf{2 4}$ from the cellular Gal4-Nurr1 hybrid reporter gene assay. Relative light units (RLU) were obtained by division of firefly luciferase data by renilla luciferase data and multiplying the value by 1000 . Although a pronounced increase in firefly activity shows Gal4-Nurr1 activation by 24, its Nurr1 activation efficacy is overestimated as a result of decreasing renilla activity. Data are the mean $\pm S E M ; n \geq 4$. 

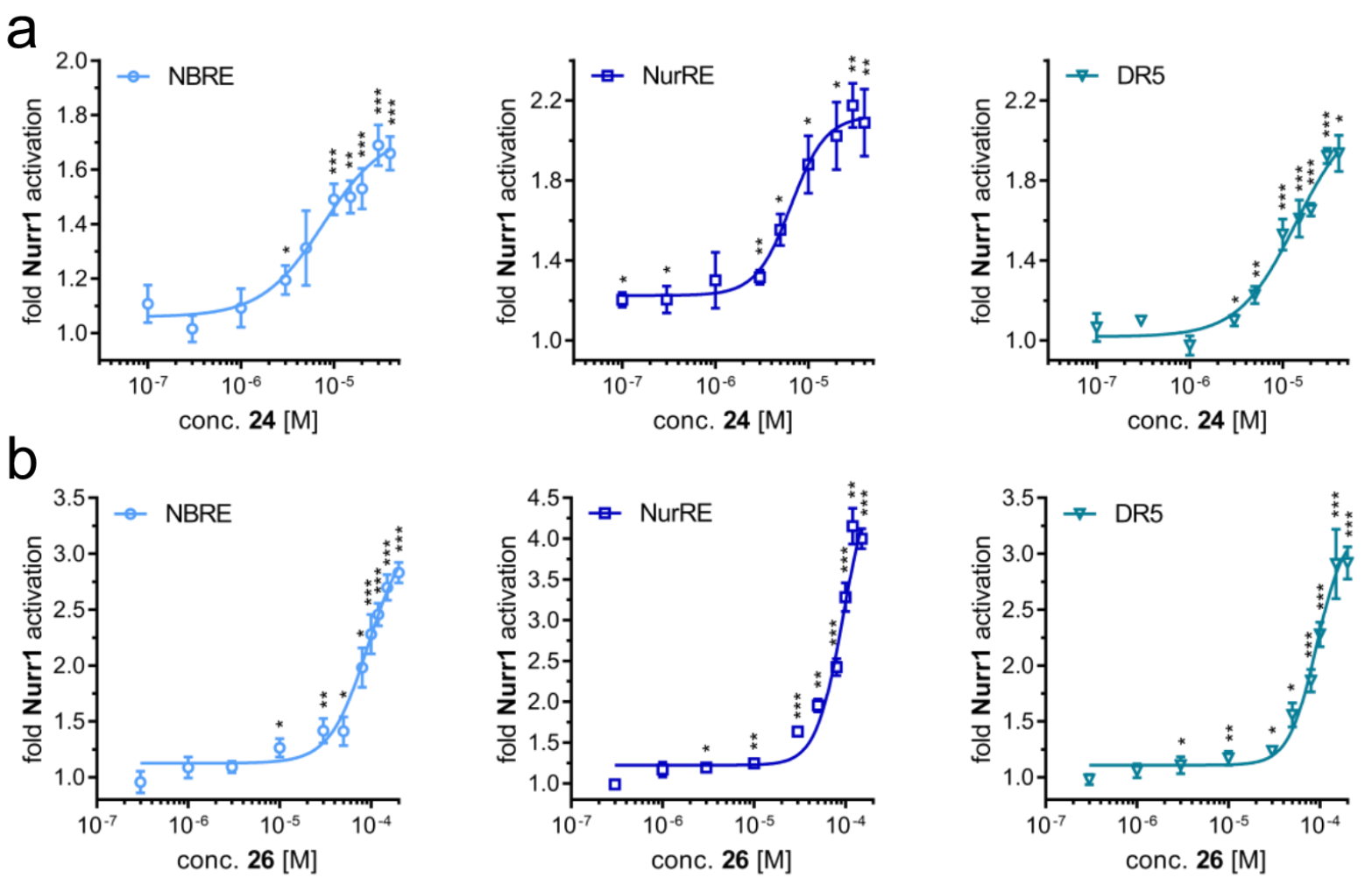

Figure S4. Activity of $\mathbf{2 4}$ (a) and $\mathbf{2 6}$ (b) in cellular full length Nurr1 reporter gene assays employing the human Nurr1 response elements NBRE (monomer), NurRE (homodimer) and DR5 (heterodimer with $R X R \alpha$ ) to govern reporter gene expression. Data are the mean $\pm S E M, n \geq 3$. Statistical significance is indicated compared to DMSO $0.1 \%$ control, ${ }^{*} p<0.05,{ }^{* *} p<0.01{ }^{* * *} p$ $<0.001$ (t-test).
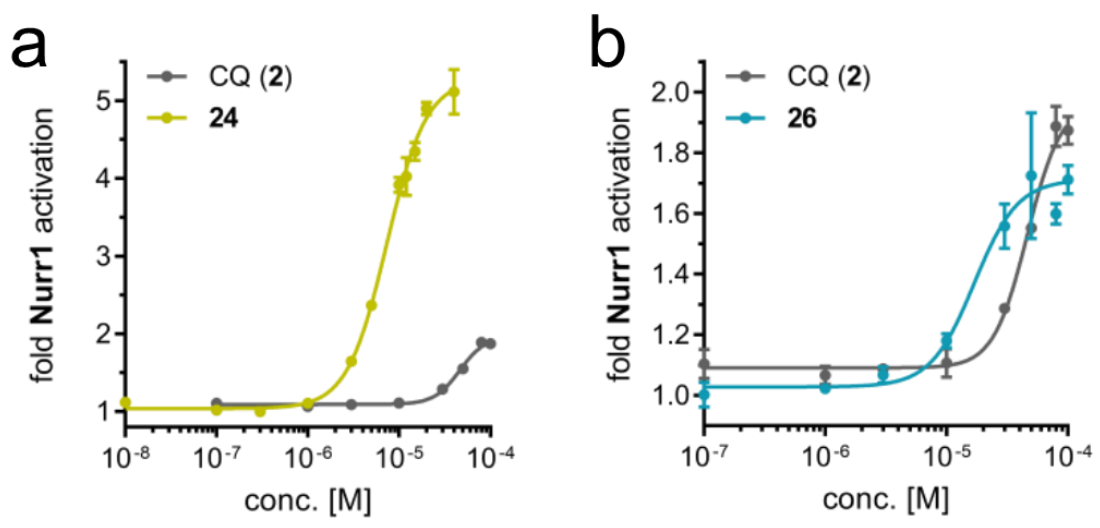

Figure S5. Activity of $\mathbf{2 4}$ (a) and $\mathbf{2 6}$ (b) in the cellular Gal4-Nurr1 hybrid reporter gene assay. CQ (2) is shown for comparison. Data are the mean \pm SEM; $n \geq 3$. 

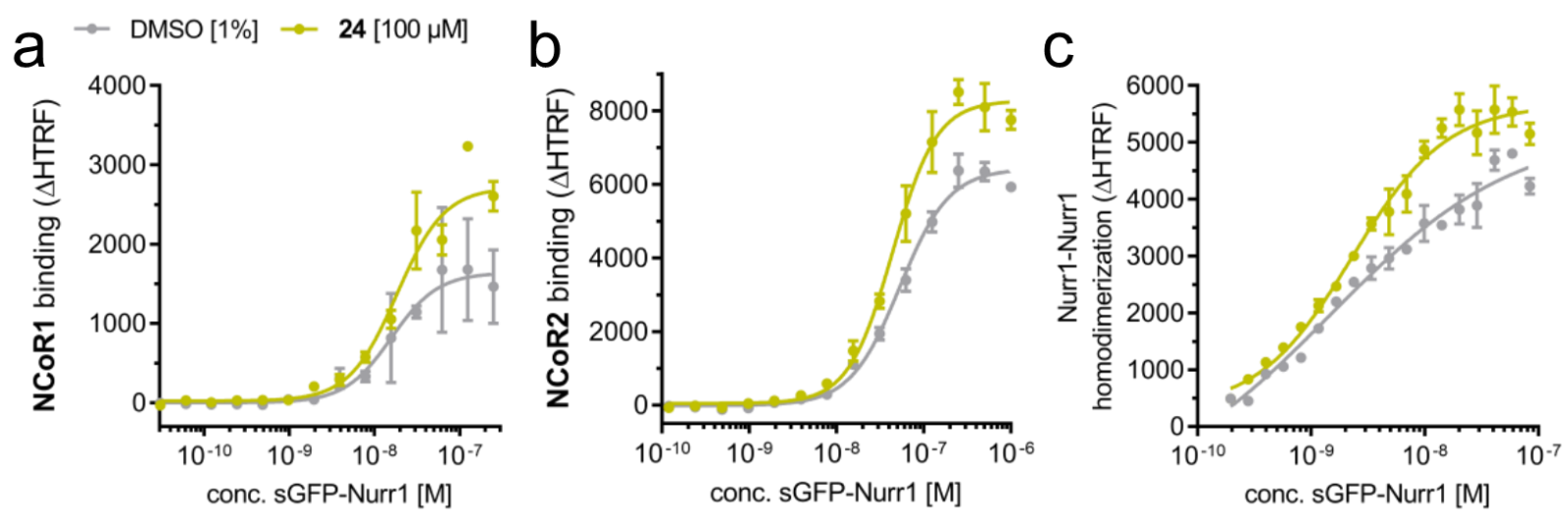

Figure S6. Effects of Nurr1 agonist 24 on co-factor binding to the Nurr1 LBD and on Nurr1 homodimerization in homogenous time-resolved fluorescence resonance energy transfer (HTRF) assays. (a) NCoR1 interaction with the Nurr1 LBD. (b) NCoR2 interaction with the Nurr1 LBD. (c) Nurr1-Nurr1 homodimerization. Data are the mean $\pm \mathrm{SD} ; \mathrm{N}=3$.

Table S1. Summarized cellular Nurr1 modulatory activities of fragments 24 and 26. The Gal4Nurr1 hybrid reporter gene assay and full length Nurr1 reporter gene assays under control of the NBRE (monomer), NurRE (homodimer) and DR5 (heterodimer with RXRa) response elements were performed in transiently transfected HEK293T cells. Values in parentheses are max. activation compared to $0.1 \%$ DMSO serving as vehicle. Data are the mean $\pm S D, n \geq 3$. Hillslopes calculated from non-linear fit ([Agonist] vs. response -- Variable slope (four parameters)).

\begin{tabular}{|c|c|c|}
\hline & 24 & 26 \\
\hline Gal4-Nurr1 & $\begin{array}{c}\mathrm{EC}_{50} 7.3 \pm 0.5 \mu \mathrm{M} \\
(5.28 \pm 0.15 \text { fold act.) } \\
\text { hillslope } 2.00 \pm 0.19\end{array}$ & $\begin{array}{c}\mathrm{EC}_{50} 17 \pm 6 \mu \mathrm{M} \\
\text { (1.71 } \pm 0.11 \text { fold act.) } \\
\text { hillslope } 2.42 \pm 1.31\end{array}$ \\
\hline $\begin{array}{l}\text { NBRE: } \\
\text { Nurr1 monomer }\end{array}$ & $\begin{array}{c}\mathrm{EC}_{50} 7.7 \pm 3.3 \mu \mathrm{M} \\
\text { (1.74 } \pm 0.16 \text { fold act.) } \\
\text { hillslope } 1.31 \pm 0.75\end{array}$ & $\begin{array}{c}\mathrm{EC}_{50} 92 \pm 21 \mu \mathrm{M} \\
(3.23 \pm 0.44 \text { fold act.) } \\
\text { hillslope } 2.09 \pm 0.71\end{array}$ \\
\hline $\begin{array}{l}\text { NurRE: } \\
\text { Nurr1 homodimer }\end{array}$ & $\begin{array}{c}\mathrm{EC}_{50} 6.5 \pm 1.6 \mu \mathrm{M} \\
(2.12 \pm 0.10 \text { fold act.) } \\
\text { hillslope } 2.31 \pm 1.21\end{array}$ & $\begin{array}{c}\mathrm{EC}_{50} 95 \pm 15 \mu \mathrm{M} \\
(4.92 \pm 0.73 \text { fold act.) } \\
\text { hillslope } 2.90 \pm 0.85\end{array}$ \\
\hline $\begin{array}{c}\text { DR5: } \\
\text { Nurr1:RXRa heterodimer }\end{array}$ & $\begin{array}{c}E_{50} 14 \pm 5 \mu \mathrm{M} \\
(2.15 \pm 0.29 \text { fold act.) } \\
\text { hillslope } 1.41 \pm 0.50\end{array}$ & $\begin{array}{c}\mathrm{EC}_{50} 92 \pm 18 \mu \mathrm{M} \\
\text { (3.24 } \pm 0.44 \text { fold act.) } \\
\text { hillslope } 2.86 \pm 1.29\end{array}$ \\
\hline
\end{tabular}




\section{Supplementary Methods}

\section{WST-1 Toxicity Assay}

WST-1 assay (Roche Diagnostics International AG, Rotkreuz, Switzerland) was performed according to the manufacturer's protocol. In brief, T98G cells and HEK293T cells were seeded in DMEM high glucose, supplemented with sodium pyruvate $(1 \mathrm{mM})$, penicillin $(100 \mathrm{U} / \mathrm{mL})$, streptomycin $(100 \mu \mathrm{g} / \mathrm{mL})$, and $10 \% \mathrm{FCS}$ in 96 -well plates at a density of $3 \times 10^{4}$ cells/well, respectively. After $24 \mathrm{~h}$, the medium was changed to DMEM high glucose, supplemented with penicillin $(100 \mathrm{U} / \mathrm{mL})$, streptomycin $(100 \mu \mathrm{g} / \mathrm{mL})$, and $1 \%$ charcoal stripped FCS additionally containing $0.1 \%$ DMSO and the test compound 2, 24 or 26 (final concentrations $0.1 \mu \mathrm{M}, 1 \mu \mathrm{M}$, $10 \mu \mathrm{M}, 30 \mu \mathrm{M}, 100 \mu \mathrm{M}$, and $300 \mu \mathrm{M}$ ) or $0.1 \%$ DMSO alone as negative control. After $24 \mathrm{~h}$, WST reagent (Roche Diagnostics International $A G$ ) was added to each well according to the manufacturer's instructions. After $45 \mathrm{~min}$ incubation, absorption (450 nm/reference, $620 \mathrm{~nm}$ ) was determined with a Spark 10M luminometer (Tecan Group AG, Männedorf, Switzerland). Each experiment was repeated at least three times in duplicates. 